\title{
PERSPECTIVAS CRITICAS DO "PRIMEIRO" GUIMARÃES ROSA
}

Patrícia Morais Rosendo

Universidade do Estado da Bahia - UNEB. Mestranda do Programa de pós-graduação em Estudos em Linguagem.

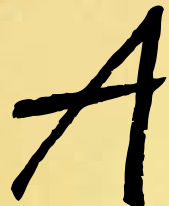

obra de um escritor como Guimarães Rosa provoca diferentes pontos de vista entre os que encaram o desafio de estudá-la. Diante da multiplicidade interpretativa promovida por meio da produção literária do autor, uma primeira dificuldade em que a perspectiva crítica se depara é o desafio de buscar uma maneira para lidar com uma obra multifacetada e de múltiplas dimensões. Assim, objetiva-se por meio deste estudo conhecer e entender como foram recebidas suas primeiras publicações, considerando os diferentes posicionamentos da crítica literária. Procura-se oferecer maior destaque às apreciações divulgadas na efervescência das primeiras publicações do escritor, noticiada por meio da crítica jornalística, levando em consideração os aspectos positivos e negativos. Para tanto, foram analisados textos críticos da ocasião em que se processou a leitura inicial da obra - a partir da década de 1940. É preciso considerar que a recepção das primeiras publicações da obra de Rosa reproduz o momento da crítica literária no Brasil, marcado pelas polêmicas e embates travados nesse âmbito. Textos de Flora Süssekind, Eneida M. de Souza e Silviano Santiago norteiam a discussão, os quais se estendem a um referencial histórico sobre o processo de transformação ocorrido na crítica literária no Brasil e a transição da crítica "não especializada" (crítica de rodapé) para a crítica especializada (crítica acadêmica). Esse período (décadas de 1940 e 1950) é um tempo de mudanças e implantação de novos modelos críticos, cujos desdobramentos se estendem até a contemporaneidade.

Palavras-chave: Guimarães Rosa. Crítica literária. Crítica de rodapé. Crítica acadêmica. 
O procedimento plástico suscitado pela obra de Guimarães Rosa acende uma série de pontos de vistas diferenciados, e uma primeira dificuldade em que a perspectiva crítica se depara é o desafio de buscar uma maneira para lidar com uma obra multifacetada e de múltiplas dimensões. Com frequência, questões centrais tratadas na fortuna crítica da obra de Guimarães Rosa são analisadas por meio de pontos de vista divergentes. É possível perceber um choque de posições críticas na recepção de sua obra, uma vez que algumas das tendências mais polarizadas - o regionalismo e o universalismo - delineiam diferentes visões acerca de um mesmo tema, que constituem questões nucleares da obra, cujas respostas podem variar muito.

Procura-se, neste estudo, dedicar maior atenção e oferecer maior destaque à crítica divulgada na efervescência das primeiras publicações do escritor, que caracterizam o período de sua estreia na literatura, noticiada por meios jornalísticos, levando em consideração tanto os aspectos positivos quanto negativos do que se falou com relação a sua produção, uma vez que apesar da extraordinária capacidade literária de Rosa, houve muita resistência à sua obra.

As matérias selecionadas para este estudo são periódicos e artigos que circularam em importantes e diferentes jornais da época, que atuavam na divulgação literária no Brasil. A abordagem problematiza as transformações ocorridas na crítica literária brasileira a partir das décadas de 1940 e 1950, bem como as tensões acerca de modelos divergentes da crítica: de um lado a crítica impressionista, a chamada "crítica de rodapé", cuja reflexão era sob a forma de resenha e tinha como principal veículo de divulgação o jornal, e do outro, um modelo ligado à "crítica acadêmica", disseminada principalmente através dos livros e da cátedra. Nesse ínterim, num cenário marcado por mudanças e implantação de novos modelos críticos, cujos desdobramentos se estendem até hoje, é que se dá a publicação das primeiras críticas relacionadas à obra de Guimarães Rosa. Assim, pesquisar sobre a crítica inicial de Guimarães Rosa é fundamental para perceber a importância das transformações por que passou a crítica literária brasileira e que fomentam o debate acerca das disputas nesse campo durante essa trajetória.

Para este estudo, selecionaram-se as seguintes matérias para apreciação: "Uma grande estreia" de Álvaro Lins, publicada pelo jornal Correio da Manhã (1946) "Um livro inédito", divulgado na revista Leitura e "Conversa de bastidores" exposto no 
jornal A casa (1946), de Graciliano Ramos e também o artigo "Grande sertão: veredas: 25 anos" de Gutemberg da Mota e Silva, publicado no Suplemento Literário de Minas Gerais em 1946.

Guimarães Rosa é hoje, segundo Eduardo Coutinho (1994), entre os escritores do século XX, talvez o mais divulgado nos meios acadêmicos nacionais e estrangeiros e detentor de uma fortuna crítica não só numericamente expressiva como também composta pelo que de melhor se vem produzindo em termos de crítica no país. Rosa obteve reconhecimento mundial pela sua produção, sendo eternizado na literatura nacional como um dos maiores escritores de todos os tempos. Contudo, nem sempre foi assim. Sua estreia no meio literário foi marcada por opiniões bem divergentes: aqueles que acolheram a obra com satisfação e teceram-lhe bastantes elogios, e aqueles que, de imediato, reprovaram-na e atacaram-na intensamente. Tais posicionamentos, que marcaram de forma decisiva a trajetória intelectual de Guimarães Rosa, se coadunam com a formação de sua fortuna crítica, demonstrando certos posicionamentos dos críticos da época. Pode-se constatar que a recusa inicial à obra rosiana decorre da quebra de paradigmas realizada pelo autor através das inovações trazidas por ele, demonstradas principalmente através de elementos que vão desde a elaboração de técnicas narrativas até inovações estruturais e linguísticas.

Ao longo do século XX, a crítica literária no Brasil passou por profundas mudanças. As transformações ocorridas no enfoque crítico se deram em função de diversos fatores, como, por exemplo, o próprio modelo de desenvolvimento da teoria literária que, ao relacionar novos conceitos e reformular sistemas teóricos, foi impulsionando a crítica a adotar também novas formas para abordar o objeto. A partir da década de 1940, no momento em que se processou a leitura da obra rosiana, a situação da teoria literária no Brasil é refletida em sua recepção, período em que se iniciam as transformações da crítica literária brasileira. Essas mudanças decorrem das visões divergentes das primeiras gerações de formandos das faculdades de Filosofia do Rio de janeiro e de São Paulo com relação às apreciações advindas de pessoas consideradas não qualificadas para exercer o papel de crítico. É num cenário dominado pela crítica jornalística que começam a delinear as posturas conflitantes acerca da atividade crítica no Brasil.

Os anos de 1940 e 1950 estão marcados no Brasil pelo esplendor da crítica de rodapé, o que significa dizer, segundo 
as considerações de Flora Süssekind (2003), uma crítica ligada basicamente a "não-especialização", que ocupava pés de página ou colunas exclusivas e contava com a colaboração de diversos nomes, dentre os quais: Álvaro Lins, Antônio Cândido, Tristão de Ataíde, Sérgio Milliet, Agripino Grieco e Mário de Andrade. A força exercida pela crítica jornalística e o prestígio oferecido via imprensa foi, sem dúvida, exemplo do poder das funções garantidas por ela também para a obra inicial de Guimarães Rosa, como relatado por Süssekind,

Outro exemplo de força, inclusive comercial, desta crítica jornalística é fornecido pelo jornal carioca A Manhã de 26 de maio de 1946: "No dia seguinte à publicação do rodapé de Álvaro Lins sobre Sagarana, a obra de Guimarães Rosa passou a ser procuradíssima nas livrarias. E essa procura continua cada vez mais intensa". (SÜSSEKIND 2003, p. 18)

Süssekind menciona, nesse trecho, o texto "Uma grande estreia", no qual Álvaro Lins apresenta a primeira obra de Guimarães Rosa. No texto, Lins anuncia ao público a presença de um novo grande livro:

O escritor apresenta uma autêntica personalidade de artista e o seu livro tem a verdadeira estrutura da criação ficcionista. Nada existe aqui a expor vacilações, deficiências, incertezas ou puerilidades de estreante [...]. Estamos diante de uma vocação de escritor que se experimentou em meditação e aprendizado técnico, de uma obra intensamente sentida e longamente trabalhada. Pelos assuntos e pelo material da construção ficcionista, pela abundância documental, pelo estilo de artista, pela riqueza e pela ciência do vocabulário, pela capacidade descritiva e pela densidade das situações dramáticas seria impossível classificar Sagarana como obra de principiante [...] (LINS, 1994, p. 67-68).

Essa apresentação de Sagarana realizada por Álvaro Lins foi bastante expressiva para divulgação da obra, uma vez que a literatura era difundida por meio de textos jornalísticos. Durante todo o artigo, Lins ressalta o potencial do escritor transmitido por meio da sua obra, destacando características que fogem ao perfil de um estreante. Para Lins, Guimarães Rosa desponta como um escritor de autêntica personalidade na vida literária, despertando e estimulando "aqueles que têm por obrigação profissional a crítica literária” (LINS, 1946, s/p), porque vale, de acordo com ele, como motivo e estímulo para manter a fé nas faculdades criadoras de sua época intelectual. 
É importante lembrar que, em 1938, Guimarães Rosa, com o pseudônimo de Viator concorreu com um livro de contos, primeira versão do que seria mais tarde Sagarana, ao prêmio Humberto de Campos realizado pela José Olympio Editora. A comissão julgadora era formada por Graciliano Ramos, Marques Rebelo, Prudente de Morais Neto, Dias da Costa e Peregrino Júnior. Rosa obtém o $2^{\circ}$ lugar, perdendo para Luís Jardim por apenas um voto. Graciliano Ramos, um dos jurados que votou contra o livro de Rosa, logo depois, no texto "Um livro inédito" ${ }^{\prime}$, fala por que votou contra Sagarana:

1 Graciliano escreveu, pelo menos, três crônicas sobre o assunto. Duas delas estão publicadas atualmente em Linhas tortas ("Um livro inédito" e "Conversa de bastidores"); a terceira foi publicada no segundo número da revista Teresa (também sob o título "Um livro inédito"). É nesta última que se encontra o trecho acima transcrito. Para este trabalho utilizou-se o texto contido em Ficção completa Vol. I, 1994.

\begin{abstract}
Votei contra esse livro de Viator. Votei porque dois dos seus contos me pareceram bastante ordinários: a história dum médico morto na roça, reduzido à condição de trabalhador eito, e o namoro mais ou menos idiota dum engenheiro com uma professora de grupo escolar. Esses dois contos e algumas páginas campanudas, entre elas uma que cheira a propaganda de soro antiofídico, me deram arrepios e me afastaram do vasto calhamaço de quinhentas páginas. (RAMOS, 1994, p. 110)
\end{abstract}

Apesar de confessar a qualidade contida na maioria dos contos do livro de Rosa, Graciliano Ramos tece uma crítica negativa, sobretudo a dois dos contos do livro. Nesse texto, Ramos versa especialmente sobre o silêncio de Guimarães Rosa após o concurso, ressaltando que "esse desconhecido é alguém de muita força e não tem o direito de esconder-se" (RAMOS, 1994, p. 110). Manifesta ainda, o desejo de que se publique o livro com todos os contos, os bons e os maus, justificando que a publicação dos "maus" levava em consideração a opinião dos outros membros do júri que figuraram o concurso. Porém, Guimarães Rosa, quando da publicação de Sagarana, oito anos após perder o concurso, suprime três dos contos, entre eles os dois criticados por Graciliano Ramos.

Em “Conversa de Bastidores", texto de 1946, Graciliano Ramos relata que em 1944 reencontra Rosa e pergunta-lhe se ele sabe que votou contra seu livro. Segundo Ramos, Rosa responde que sim, sem demonstrar ressentimentos. Graciliano Ramos narra que na breve conversa percebeu-se diante de uma inteligência livre de mesquinhez e falou-lhe sobre os defeitos do livro que guardara na memória. Rosa, concordando, comunica-lhe que havia suprimido os contos mais fracos e retificara os restantes, alheio aos futuros leitores e à crítica.

Esse episódio marca de forma definitiva a carreira literária de Guimarães Rosa. As observações críticas realizadas por 
Graciliano Ramos fizeram com que o livro passasse por longa depuração e revisão adquirindo consistência para a publicação. As advertências de um já consagrado escritor se constituíram como fundamentais para configurar o sucesso de Sagarana como um livro que ampliou de forma significativa o território cultural de uma literatura dita regionalista. Concluindo o texto "Conversa de bastidores", Ramos finaliza proferindo: "certamente ele fará um romance, romance que não lerei, pois se for começado agora, estará pronto em 1956, quando os meus ossos começarem a esfarelar-se" (Ramos, 1986). De fato, em 1956, como prenunciado por Graciliano Ramos, Rosa publica aquele que seria considerado um dos melhores romances da literatura no Século XX, Grande sertão: veredas, e o mestre Graciliano Ramos não estava mais aqui para apreciá-lo.

A crítica de rodapé agia num terreno fértil para a literatura, sobretudo nas décadas que se seguiram ao modernismo, quando Rosa despontava no meio literário. No entanto, a partir da década de 1950 a crítica impressionista no Brasil começa a perder fôlego, no momento em que os acadêmicos advindos das recém-criadas faculdades de filosofia, ciências sociais e letras, providos de conceitos teóricos, interessados na especialização e na pesquisa acadêmica ocupam o espaço dedicado à literatura nos jornais, e a atividade, antes exercida pelos "homens das letras", ganhou novos colaboradores, ampliando os campos de domínio e o prestígio do crítico universitário.

O enfoque dado por Flora Süssekind (2003) em Papéis Colados nos estende um referencial histórico sobre o processo de transformação ocorrido na crítica literária no Brasil. A autora aponta duas linhas de força que marcariam o pensamento crítico brasileiro seguinte: o jogo dialético de Antônio Cândido e a crítica estética de Afrânio Coutinho, as duas principais opções intelectuais da época - cada um desempenhando a atividade crítica a sua maneira, com estilos e modos próprios de refletir sobre a literatura e a própria crítica. As posturas conflitantes da crítica encontram seu auge nos embates travados entre os críticos scholars e os "jornalistas", representada especialmente pela polêmica tomada entre Afrânio Coutinho e Álvaro Lins que protagonizaram um combate que durou quase dez anos. Para Süssekind, ao escolher Álvaro Lins como alvo, Afrânio Coutinho não o fez de forma desinteressada:

A escolha do alvo não era evidentemente gratuita. Tratava-se de um dos críticos mais poderosos da época. Atingi-lo era, então, acertar em cheio nos próprios 
mecanismos de qualificação intelectual vigentes. Era abalar o sistema literário que fizera de "imperador". E, com isso, se abriria espaço para um outro tipo de critério de avaliação profissional, para uma substituição do jornal pela universidade como "templo da cultura literária" e da figura do crítico enciclopédico e impressionista, com sua habilidade para a crônica, pela do professor universitário, com seu jargão próprio e uma crença inabalável no papel "modernizador" que poderia exercer no campo dos estudos literários. Tratava-se, em suma, de substituir o rodapé pela cátedra. E conquistar o poder até então em mãos de não especialistas para as daqueles dotados de "aprendizado técnico", nas palavras de Afrânio Coutinho. Isto é, para os críticosprofessores. (SÜSSEKIND, 2003, p. 22).

Ao retornar, por volta de 1948, de uma temporada de estudos nos Estados Unidos, Afrânio Coutinho veio com a incumbência de instituir no Brasil uma crítica literária de caráter científico, influenciado pelo New Criticism americano. O professor baiano encontrava-se tomado pelo anseio de revolução/ renovação das questões concernentes à literatura. Na tentativa de estabelecimento de uma Nova Crítica e do seu estatuto de ciência, essa nova perspectiva inclinava-se, segundo Eneida Maria Souza (2002), ao uso exacerbado de métodos e teorias de análise literária.

Visando instituir nas universidades brasileiras espaço para se falar de literatura, Afrânio Coutinho inicia o movimento em prol de uma literatura mais autônoma e de uma crítica pautada nos valores estéticos. Esse novo modelo de crítica prezava por um estudo imanente do texto, utilizando suas análises técnicas minuciosas, focando nos elementos intrínsecos do texto e eliminando qualquer artifício que fosse considerado extratextual. Logo, Coutinho tinha a missão de acabar com a crítica amadora dos rodapés literários atacando, principalmente, o mais prestigiado dos críticos impressionistas da época: Álvaro Lins. Com isso, atingi-lo era então acertar em cheio os próprios mecanismos de qualificação intelectual abalando o sistema literário vigente, como bem afirmou Süssekind. Nesse viés, se intensificam as disputas entre as duas vertentes e ambas passam a ocupar lado a lado as páginas da imprensa diária.

Eduardo Coutinho (1994) assevera que, após a publicação de Grande sertão: veredas, as posições críticas acerca da obra rosiana, tanto a apologética quanto a restritiva, que apreenderam a obra por meio de uma visão unilateral, sofreram séria revisão. Apesar de Grande sertão representar o livro que consagrou 
2 Os textos publicados no Suplemento Literário de Minas Gerais reproduzem uma parcela da crítica, que sempre foi favorável à obra de Guimarães Rosa. Nesse texto, em particular, o crítico indica as duas vertentes da crítica.
Rosa na literatura e ser considerado o mais bem elaborado dentre os livros do autor, é possível perceber que o clássico não tem uma recepção tão empática, como mostra o artigo de Gutemberg da Mota e Silva publicado, em setembro de 1981, no Suplemento Literário de Minas Gerais ${ }^{2}$. Intitulado "Grande sertão: veredas, 25 anos". O artigo registra as duas faces da crítica literária acerca da obra do escritor mineiro: os que o atacaram ferozmente e os que o aplaudiram sem ressalvas.

No artigo, o crítico coloca lado a lado as opiniões de escritores renomados e críticos impressionistas que divergiam a respeito do livro.

Enquanto escritores como Agripino Grieco, Marques Rebelo, Umberto Pelegrino e Ferreira Gullar admitiam à revista Leitura que não haviam conseguido passar dos primeiros capítulos, Cavalcanti Proença, Tristão de Athayde, Da Costa e Silva, Drummond, Oswaldino Marques e outros proclamavam entusiasmados os seus méritos. (SILVA, 1981, s/p)

A publicação da revista Leitura mencionada acima se0 refere a uma seção especial, publicada em 1958, que tinha como título "Escritores que não conseguem ler Grande sertão: veredas", em que reunia depoimentos de vários escritores. Entre os "maus" leitores, além dos citados acima, estavam nomes como o do escritor e crítico literário baiano Adonias Filho. Uma matéria da revista Veja, de 1999, que faz referência a essa publicação de 1958 da revista Leitura, traz a seguinte declaração de Ferreira Gullar: "Li setenta páginas do Grande sertão: veredas. Não pude ir adiante. A essa altura, o livro começou a me parecer uma história de cangaço contada para linguistas" (GULLAR, 1958) Opiniões como e do poeta e crítico Ferreira Gullar acerca do livro não são exceções, posto que outros intelectuais também ponderam desse juízo.

A título de configurar esse panorama apresentam-se algumas dessas declarações trazidas por Mota e Silva em seu artigo: Ascendino Leite registrou em seu diário literário que nunca ouvira dizer que com ilegibilidade se pudesse edificar uma literatura. O romancista Ivan Pedro Martins, embora reconhecesse o talento de Guimarães Rosa, acusava-o de possuir uma linguagem esotérica e, por conseguinte, a incapacidade de comunicação. Por sua vez, o escritor e crítico baiano Adonias Filho considerava o livro um "matagal indevassável" (SILVA, 1981 , s/p). Mota e Silva chama a atenção para o fato de que mesmo depois de passados vinte anos da publicação de Grande 


\section{adenows \\ ESPUC \\ BELO HORIZONTE - N. 28 - 2016}

\section{Patricia morais Rosendo}

sertão: veredas o crítico continuava irredutível, mantendo a sua opinião.

Com relação às dificuldades encontradas na leitura de Grande sertão: veredas, Kathrin $H$. Rosenfield (2008) sublinha que, apesar da complexidade encontrada na obra rosiana, o livro não é mais considerado um romance ilegível, a autora destaca que o clássico Grande sertão: veredas nunca esteve entre as preferências do grande público, contudo, salienta que dentre as múltiplas dimensões que mobilizam os leitores de Rosa, percebe-se que vem se configurando uma razoável mudança relacionada a esse aspecto. A recusa pela obra de Guimarães Rosa, num primeiro contato, certamente está associada a questões inerentes aos deslocamentos e rupturas realizadas em torno da construção tradicional do texto e, sobretudo, a questões relacionadas ao léxico utilizado pelo autor. Entretanto, é importante lembrar que na obra de Rosa nada é por acaso, existe sempre a intencionalidade de alcançar, atingir, criticar, mostrar, construir ou desconstruir algo em suas narrativas, por isso, na criação de cada texto havia uma preocupação constante e, segundo Antônio Callado, o próprio Rosa dizia que queria que se dedicassem a entendê-lo, "ele exigia esse esforço das pessoas”. (CALLADO, 2011, p.13).

O artigo de Gutemberg da Mota e Silva (1981) também apresenta a crítica favorável ao autor. Dentre os admiradores do Grande sertão: veredas estão nomes como o de Sérgio Milliet o qual apontou que o romance "foi o grito de independência da nossa literatura" (SILVA, 1981, s/p), assinalando que o livro é um acontecimento literário e linguístico do século. Apresenta também as considerações de Antônio Cândido que classificou o livro como obra-prima: "tudo é forte, belo, impecavelmente realizado" (SILVA, 1981, s/p). No mesmo artigo, Carlos Drummond de Andrade não poupou elogios, ressaltando que sua linguagem é uma saborosa invenção. O crítico e tradutor Paulo Rónai afirma que Guimarães Rosa criou algo sem precedentes em nossas letras e provavelmente, em qualquer literatura. $\mathrm{O}$ depoimento de Afonso Arinos de Melo Franco chama atenção e vale também como alerta para os leitores iniciantes da obra de Rosa:

Ciente dessa dificuldade, Afonso Arinos de Melo Franco advertia: "cuidado com este livro, pois Grande sertão: veredas é como certos casarões velhos, certas igrejas cheias de sombra. No princípio, a gente entra e não vê nada. Só contornos confusos, movimentos 
indecisos, planos atormentados. Mas, aos poucos, não é luz nova que chega: é a visão que se habitua. E, com ela, a compreensão admirativa. O imprudente ou sai logo, e perde o que não viu, ou resmunga contra a escuridão, pragueja, dá rabanadas e pontapés. Então, arrisca-se chocar inadvertidamente contra coisa que, depois, identificará como muito belas. (FRANCO, in: SILVA 1981, s/p).

A metáfora utilizada por Afonso Arinos é oportuna conquanto traduz e explica de forma admirável muitas das críticas negativas mostradas no artigo, que em sua maioria, são de intelectuais que não ultrapassaram se quer as primeiras páginas do livro, como é o caso de Ferreira Gullar, que confessa ter lido somente umas setenta páginas e não ter ido adiante. Ou seja, muitos deles não souberam lidar com o caos inicial das primeiras páginas do Grande sertão, não ousaram se arriscar na escuridão a fim de adaptar suas visões para compreender e admirar a beleza cifrada no livro.

A periodização das publicações da obra de Guimarães Rosa se estende de 1946, ano em que foi publicado Sagarana, sua primeira obra, até 1970, ano de publicação de Ave Palavra, livro póstumo, publicado três anos após a morte do autor. Nessa época, os embates no campo da crítica literária se intensificaram, pois a partir do final da década de 1960 e início da década de 1970, com a implantação dos primeiros cursos de pós-graduação no Brasil, começa a delinear um panorama de uma crítica mais acadêmica e especializada, em detrimento da crítica jornalística. A crítica do jornal, considerada como humanista perde espaço para a crítica que se quer científica. Os intelectuais universitários e os críticos especialistas interessamse, sobretudo, em construir seu objeto, sempre vinculado a uma corrente teórica que a impele a se ater às leituras que respaldam suas visões. Para Eneida Maria de Souza (1993) o que importa para essas correntes teóricas é o objeto de análise, deixando o sujeito reduzido a segundo plano.

Para Silviano Santiago (2004) é uma ironia o fato de que o principal responsável pelo afastamento da avaliação da obra literária no jornal tenha sido o professor das faculdades de Letras. Santiago acrescenta que, inconformados com o impressionismo da crítica literária produzida por intelectuais sem formação acadêmica, os professores universitários, munidos de conceitos teóricos, afastaram de forma definitiva os "verdadeiros formadores de opinião", endossando que a "campanha sistemática contra os não especialistas serviu 
para esvaziar de vez a grande imprensa de uma contribuição, talvez aqui e ali um pouco manca, mas sempre de muito boa qualidade." (SANTIAGO, 2004, p.165).

Em concordância com as exposições proferidas por Silviano Santiago, reconhecem-se os vários pontos positivos e os ganhos teóricos proporcionados pelas universidades. No entanto, é preciso que as novas gerações de universitários tenham acesso e estudem o célebre trabalho desenvolvido por escritores brasileiros e que se abram possibilidades de uma leitura crítica, no espaço do jornal e da revista, "espaço necessário para discussão de ideias, o espaço indispensável e generoso para o pensamento criterioso e opinativo". (SANTIAGO 2004, p.166).

Essas considerações a respeito da crítica de Guimarães Rosa no momento de suas primeiras publicações são complacentes, visto que reverbera uma das principais funções desenvolvida pelos críticos: o papel de mediador entre a obra e o leitor. Apesar das transformações ocorridas no campo da crítica, ela ainda possui grande influência sobre o público, transformando-se no elo que aproxima o passado e presente, isto é, o crítico é o intermédio entre o momento de produção da obra e o mundo do leitor, portanto, de fundamental importância para perpetuação da obra literária.

\section{CRITICAL PERSPECTIVES OF GUIMARÃES ROSA'S "FIRST"}

\section{ABSTRACT}

The work of a writer as Guimarães Rosa causes different points of view among those who face the challenge of studying it. Due to the interpretative multiplicity promoted by the author's literary production, a first difficulty faced by the critical perspective is the challenge of searching for a way to deal with a multifaceted work with multiple dimensions. In this sense, this study aims to know and to understand how Rosa's first publications were received, taking into consideration different positioning of literary criticism. We want to highlight the appreciations disclosed in the effervescence of Guimarães Rosa's first publications, informed by the journalistic criticism, taking into consideration their positive and negative 
aspects. For such, we analyzed critical texts from the period of his work's first readings - from the 1940s on. We should consider that the reception of his first publications reflects the moment of literary criticism in Brazil, marked by controversies and discussions in this area. Texts by Flora Süssekind, Eneida M. de Souza, and Silviano Santiago guide the discussion, which extends to a historical referential on the process of transformation that occurred in the literary criticism in Brazil and the transition from the "non-specialized "criticism (footnote criticism) to specialized criticism (academic criticism). This period (decades of 1940 and 1950) is a time of changes and implementation of new critical models, whose unfolding is extended through contemporaneity.

Keywords: Guimarães Rosa. Literary criticism. Footnote criticism. Academic criticism.

\section{REFERÊNCIAS}

CALLADO, Antonio. Depoimentos sobre João Guimarães Rosa e sua obra. São Paulo: Nova Fronteira, 2011.

CÂNDIDO, Antônio. "O homem dos Avessos". In: CÂNDIDO, Antônio. Tese e Antítese. 4.ed. - São Paulo: T. A. Queiroz, 2000.

COUTINHO, Eduardo F. "Guimarães Rosa: um alquimista da palavra”. In: COUTINHO, Eduardo F. Ficção completa de Guimarães Rosa, vol. I. Rio de Janeiro: Nova Aguilar, 1994.

LEENHARDT, Jacques. MARTINS, Maria Helena (Org.). "Crítica de arte e cultura no mundo contemporâneo". In: Maria Helena (Org.). Rumos da Crítica. São Paulo: SENAC; Itaú Cultural, 2000.

LINS, Álvaro. "Uma grande estreia". In: COUTINHO, Eduardo F. Ficção completa de Guimarães Rosa, vol. I. Rio de Janeiro: Nova Aguilar, 1994.

LORENZ, Günter. "Diálogo com Guimarães Rosa”. In: COUTINHO, Eduardo F. Ficção completa de Guimarães Rosa, vol. I. Rio de Janeiro: Nova Aguilar, 1994.

RAMOS, Graciliano. "Conversa de bastidores”. In: RAMOS, Graciliano. Linhas tortas. Rio de Janeiro: Record, 1986.

RAMOS, Graciliano. "Um livro inédito". In: COUTINHO, 
Eduardo F. Ficção completa de Guimarães Rosa, vol. I. Rio de Janeiro: Nova Aguilar, 1994.

Revista Veja, 13/10/199. Edição 1.619. Acesso em: 10/01/2015. Disponível em: HYPERLINK "http://veja. abril.com.br/131099/p_142.html.\%20Acesso\%20em\%20 10/01/2015.N" http://veja.abril.com.br/131099/p_142.html. Acesso em 10/01/2015.N

ROSA, João Guimarães. Ficção completa vol. I. Rio de Janeiro: Nova Aguilar, 1994.

ROSA, João Guimarães. Ficção completa vol. II. Rio de Janeiro: Nova Aguilar, 1994.

ROSENFIELD, Holzermayr Kathrin. Grande sertão: veredas - Roteiro de leituras. Rio de Janeiro: Topbooks Editora, 2008.

SANTIAGO, Silviano. "A crítica literária no jornal". In: SANTIAGO, Silviano. O cosmopolitismo de pobre: crítica literária e crítica cultural. Belo Horizonte: UFMG, 2004.

SILVA, Gutemberg da Mota e. "Grande sertão: veredas, 25 anos". Minas Gerais, Belo Horizonte, 12 de set. 1981. Suplemento Literário.

SOUZA, Eneida Maria de. "Querelas da Crítica”. In: SOUZA, Eneida Maria de. Traço Crítico: ensaios. Rio de janeiro: UFRJ; Belo Horizonte: UFMG, 1993.

SOUZA, Eneida Maria de. "Os livros de cabeceira da crítica". In: SOUZA, Eneida Maria de. Crítica Cult. Belo Horizonte: UFMG, 2002.

SÜSSEKIND, Flora. "Rodapés, tratados e ensaios: a formação da crítica brasileira moderna." In: SÜSSEKIND, Flora. Papéis Colados. 2. ed. Rio de Janeiro: UFRJ, 2003.

Templo Cultural Delfos. Guimarães Rosa e o Magma. Disponível em: http://www.elfikurten.com.br/2011/02/ guimaraes-rosa-e-o-magma.html.

VASCONCELOS, Sandra Guardini T. MARTINS, Maria Helena (Org.). "Apresentação de Jacques Leenhardt". In: Maria Helena (Org.). Rumos da Crítica. São Paulo: SENAC; Itaú Cultural, 2000.

Recebido em: 22/06/2015

Aceito em: 25/04/2016 